DOI: 10.24234/wisdom.v17i1.448

Yuliia BUTKO, Leonid MOZHOVYI, Viktoriia SLABOUZ

\title{
PHILOSOPHICAL HERMENEUTICS BY H.-G. GADAMER: TRANSITION FROM INTERPRETATION TO UNDERSTANDING
}

\begin{abstract}
The static and dimensional nature of classical philosophy under the conditions of the information multimedia society is transformed into a rapid nonlinear acceleration of all cultural processes. This new phase of dynamic changes in culture was first of all revealed using the comparative analysis of different natural languages, the search for their unity, and, as a consequence, the possibilities of their application to explain the phenomena of today's reality. That is why the ambiguity of the linguistic and intellectual view on the humanities culture becomes the subject of study of hermeneutic currents in modern philosophy. And since the problems of disagreements in postmodern philosophy have not been resolved yet, the analysis of the primary sources of philosophical hermeneutics and its formation at the level of the deep foundations of functioning (first of all, at the level of interpretation of various manifestations of culture as peculiar features of the existence of society in the $21^{\text {st }}$ century) is one of the most relevant and urgent research problems.
\end{abstract}

Keywords: hermeneutics, text, theory of understanding, interpretation, modern philosophy.

Introduction

Even a cursory review of modern philosophy indicates that it has accumulated many problems that cannot be solved within the classical view of the essence of general cultural events. The term "non-classical philosophy" refers to a new era of culture, in which fundamentally new ideas in the understanding of reality have appeared. Most modern researchers associate this with forming linguistic, semantic, or mental transmissions of modern philosophy and culture.

For these reasons, the concepts of the founders of philosophical hermeneutics - F. Schleiermacher, W. Dilthey, H.-G. Gadamer - have been analysed in detail by many recognised critics of the traditional methodological concepts of cognition, such as G. Shpet, P. Ricœur, Ju. Kristeva, P.-M. Foucault, G. Deleuze, R. Barthes, and some others, but from different angles. These authors have once again emphasised that the researchers of the humanitarian direction need to move away from understanding hermeneutics as a traditional art of interpreting texts like the ancient explanation of the will of the gods to mere mortals or, by analogy with the medieval summing up of the will of a Christian under its dependence on religious dogmas. On the contrary, when interpreting the text, one must abstract from the logic of its content (namely, from the 
causal-consequent principle of its construction) and make an attempt to discover the author's individuality, veiled by the logic of the content, and with the help of this feature, reveal the hidden author's intention of the work. In other words, the essence of any work is the realisation of the author's individuality, his/her uniqueness. So, the genius of the text, its peculiarity is revealed to the researcher only through his/her sympathy, empathy with the author's thought. The researcher of the text appears to be its interpreter, namely, a person who seeks in himself/ herself, in his/her fundamental forces, the embodiment of the author's individuality. In this context, hermeneutics' essence is revealed in the form of a particular methodological approach, which is entirely appropriate to represent the "hermeneutic circle", which implies closure only in the case of finding harmony between the spiritual essences of the author and the interpreter. From these positions, modern philosophy should clearly distinguish between the peculiarities of cognition of natural reality (although today it appears before us as a veiled, disguised, indefinite reality, without a predetermined necessity) and cultural-historical reality.

The point is that cultural and historical reality cannot be interpreted as a simple conglomeration of disparate facts that need to be comprehended and logically combined with a subsequent making and elucidation of the conclusions. On the contrary, it is subject to human consciousness only through the refraction of the researcher's mental abilities, namely, when the latter falls into the object of research, merges with it, becomes a part of it, and experiences its history. Thus, the clearly defined referent of subject-object relations, successfully embedded in the philosophy of the Modern era in the methodology of cognition, ceases to play a fundamental role in research and cultural-historical reality for the interpreter acquires signs of vital integrity.

It seems that for these reasons, the analysis of hermeneutic concepts in the context of their combination with the peculiarities of the modern phenomenological tradition occupies an important place in the works of famous Ukrainian philosophers such as Ye. Bystrytskyi, I. Bychko, B. Holovko, V. Zahorodniuk, S. Krymskyi, A. Karpenko, V. Kuplin, A. Loi, V. Liakh, V. Malakhov, V. Okorokov, V. Pazenko, M. Popovych, Ye. Prychepii, L. Sytnychenko, V. Tabachkovskyi, etc. These researchers are united by the conclusion that the understanding of the culturalhistorical reality of man should be sought in himself/herself as a consequence of experience. And what a person experiences, he/she finds in another through understanding. That is, the fact of understanding is identified directly with the tendency of self-understanding because a person in the individuality of another can recognise what he/ she finds as fundamental to his/her self only.

\section{Statement of Basic Material}

Thus, hermeneutics can rightly be positioned not only as a general theory of understanding and interpretation but also as a methodology that can shed light on the fundamental problems of the humanities and develop a universal instrumentarium with high heuristic value. These two approaches to the understanding of hermeneutics (that is, as a general theory and methodology) have been very quickly supplemented by a third direction - separate hermeneutic studies conducted in the field of humanitarian knowledge. The subject matter of interpretation and understanding, the principles of constructing schemes of interpretation have appeared to be in demand in linguistics, cultural studies, history, 
literature, in various conterminous disciplines that link psychoanalysis, social anthropology, logic and philology, structuralism, and cognitivism.

The debates over the interpretation of hermeneutics as a particular methodology are of particular importance today. The fact is that in the $21^{\text {st }}$ century, the general idea of society as a well-established mechanism that unfolds through the implementation of the functional integrity of its elements is collapsing. If earlier society assumed interpretation in the form of a system with a clearly defined structure and man's role in this structure was limited to various ways of socialisation, which ensured cohesion, the process of uniting persons, now it is losing its organic integrity. As V. Liakh positively points out in this regard when criticising the position of the wellknown sociologist and political philosopher of our time Z. Bauman regarding the situation in society, "....after the recognition of the new reality as the era of Postmodernism, all humanities inevitably face a rather difficult task: to reformat the entire set of cognitive instruments and methodological approaches, accordingly abandoning their previous achievements and methods of comprehending reality. Moreover, this is an excruciating procedure because the stakes are very high: at stake, it is the whole array of humanities. After all, this raises a rather acute issue: to what extent are the previous methodology and paradigms of thinking suitable for describing the new reality?" (Liakh, Yosypenko, Liubyvyi, Pazenok, Raida, \& Sytnychenko, 2017, p. 6).

However, the search for a new methodology of cognition of the historical-cultural reality of the present still remains at the level of a "sensation of the modern method", which is not yet clearly realised and comprehended, and therefore cannot claim scientific significance. The situa- tion of "method search" is complicated by the fact that in modern society, the peculiarities of the fundamental forces of man are manifested, mostly in the form of individualism, i. e., the extreme, uttermost form of individuality, which is caused by a particular attitude to masked and uncertain reality. Furthermore, this becomes quite obvious because the lifestyle has changed dramatically, which now interprets the desire for freedom as an opportunity for self-defence, and the feeling of satisfaction in many cases is identified solely with the achievement of pleasure in all its diversity. Therefore, the issue of applying the hermeneutic tradition of philosophising to the context of modern historical-cultural reality, taking into account the whole palette of its peculiarities, is relevant and deserves attention.

It is well known that the development of German philosophical hermeneutics found its logical conclusion in the hermeneutic project by H.-G. Gadamer as the final phase of the development of the range of ideas of German philological hermeneutics of the $19^{\text {th }}-20^{\text {th }}$ centuries. However, for our study, it is interesting that for Gadamer, hermeneutics deals primarily not with the methods of the humanities but with universal models of understanding and interpretation. Moreover, he refers the universality not only to the range of objects of understanding but to culture as a whole, which is organised based on language and only then is transferred into the plane of understanding as a special methodology. Sometimes it even seems that the hermeneutic method unfolds contrary to generally accepted scientific principles (Liakh, Yosypenko, Liubyvyi, Pazenok, Raida, \& Sytnychenko, 2017, pp. 118-125). And from the philosophical point of view, this contradiction is perceived as entirely objective because the truth cannot be reduced only to the truth of the proposals. On the contra- 
ry, there are various forms of truth, such as the truth of a work of art, the truth of religion, and morality, which are no less important to humans than the truth of science. The objectivity of scientific truth is opposed by the importance of the norms of the living world. Scientific truth and the truths of life are equally necessary and mutually complementary. It follows that the hermeneutic method is presented by Gadamer as a "universal aspect of philosophy" (Gadamer, 1991, p. 55). Nevertheless, what are its universality and practical significance for philosophical research?

First of all, it should be noted that Gadamer traditionally begins to think about finding a method for interpreting texts, namely, their interpretation. However, he tries to deviate as much as possible from the propositional textual content, which is based on the standard (denotative) meanings of language signs and the connections between them. For him, the text is, first of all, a complex conglomeration of meanings, which assumes a specific set of variations. Its primary purpose is to be a means of conversation.

Of course, any speech depends on language, and one can create a science only about language, but not about speech. It seems that this conclusion is successfully substantiated by the recognised representatives of structuralism (F. de Saussure, K. Levi-Strauss, R. Jacobson, and others), and it became the key to Gadamer's departure from the generally accepted principles of linguistic structure: the transition of hermeneutic studies to the sphere of conversation, stories, and other aesthetic formations is devoid of scientificity and therefore deserves attention. However, any aesthetic formation is an act, a process of free combination of signs and therefore presupposes the existence of a subject-author. However, the author only uses language (in its broadest sense) as a historical-cultural fact with all its in- herent rules that do not change at the author's will. Thus, any text must be considered from the standpoint of several components: the internal content (which is a subject-matter issue of scientific interest) and the author, title, beginning, and end. Moreover, Gadamer uses the term "text" in a much broader sense than a simple linguistic formation. "Every work of art," the researcher writes, "not only literary, must be understood like any other text which is under understanding, and such an understanding must be mastered" (Gadamer, 1988, p. 215).

Nevertheless, how to carry out this mastery? After all, theoretical knowledge here recedes into the background, opening a springboard for the realisation of direct experience, or life experience, which consists of various forms of historical practice and aesthetic worldview. It follows that the repository of experience is not only language but also art because "the sciences of the spirit converge with such ways of comprehension that lie outside science: with the experience of philosophy, with the experience of art, with the experience of history itself. All these are such ways of comprehension in which the truth which is not subject to verification by methodological means of science informs about itself" (Gadamer, 1988, p. 39). It is in this context that the "sensation of the method" of hermeneutic studies must be understood.

Thus, Gadamer, in his reflections on the method, proceeds from the concept of "hermeneutic experience", which in his interpretation contains not only linguistic experience (so successfully used by famous structuralists in their studies) but also historical, life experience. As for the latter, it is impossible without taking into account the diversity of unconscious intentional acts, elements of "pure" consciousness, which produce a kind of preliminary understanding of a 
particular process, but within the historical tradition. This pre-understanding (or premonition) has nothing in common with the methodological tradition of research formed during the New Age era and was based on the foundations of intellectual intuition, successfully considered by R. Descartes. On the contrary, it often goes beyond implicit (causal-consequent) relationships, even when substantiating scientific truths. "The phenomenon of understanding not only permeates all human connections with the world," writes Hans-Georg Gadamer on this subject. "Also in science, it has an independent meaning and opposes all attempts to turn it into any scientific method" (Gadamer, 1988, p. 39). Even the historical tradition, within which the life and thinking of the interpreter are carried out, recedes into the background in hermeneutic research because the close connection of the "present being" of the interpreter with his past is a kind of burden, an obstacle to the knowledge of the true essence and value of the process under understanding. In other words, in hermeneutic experience, it is not only the retelling of the text (in the broadest sense of the term) that deserves attention but also the subject who understands it, that is, the interpreter. Understanding the text from this point of view is not a simple interpretation or explanation but an immersion of the interpreter in the subjectivity of the author of the text. And immersion here should not be understood as a simple, mirror-image transfer to the subjectivity of another. On the contrary, Gadamer states only the reconstruction of the author's life-world, that is, the reproduction of his life experience, through which each of us understands the meaning of the existence of culture, its certain attractions. Moreover, in this sense, the category of "understanding" appears before us much higher than the hermeneutic interpretation, which was success- fully used as a method of explanation, interpretation of ancient and medieval texts. That is why the researcher dwells on the essence of this category and its role in hermeneutic experience in more detail.

H.-G. Gadamer proceeds from the fact that the carrier of understanding is language, and the function of explication of language signs is performed by thinking. Nevertheless, to make this explication, a person needs education (Bildung, paideia). The researcher believes that this word is now "most closely associated with the concept of culture and means a specifically human way to build the natural data and capabilities of the individual" (Gadamer, 1988, p. 19). In other words, through education, a person makes himself a spiritual being. Moreover, the peculiarity of the humanities is rooted in the fact that they hint at the already formed scientific consciousness, which can neither be learned nor imitated. It is thanks to this scientific consciousness, which now exists ostensibly in the form of a predetermined one, that judgments in the humanities are built, as well as the means of their understanding and application.

However, the humanities, Gadamer is deeply convinced, approach the interpretation of the scientific category of "truth" somewhat differently. They believe that understanding uses the transcendental component of the human self to reveal the truth. For this reason, Gadamer calls for a departure from the traditionally modern allobjective paradigms of the human "Self" and to plunge into the transcendent abyss of the human self, which is characterised by shades of compassion, justice, responsibility, freedom, etc. which are actualised from outside the angle of causalconsequent relationships and hope for reciprocity on the part of other people.

Gadamer closely associates the category of 
"method" with the category of "truth", although he repeatedly insists that he does not set himself the task of developing the newest method of cognition. It seems to us that the category of "method" in the researcher's teaching appears to be auxiliary, namely, one by which a person can achieve the "truest" interpretation of a work of culture when applying the transcendental moments of his own "Self".

Actualising the transcendental moments of the human "Self" during understanding indicates the presence in the knowledge of certain forms of experience that are not subject to scientific verification. For example, the experience of communication cannot be equated with the sciences of communication. Moreover, in general, any feeling of beauty, emotions from the experience of a particular work of culture cannot be replaced by aesthetics, as the science of beauty. Finally, there are well-known examples when a person perfectly masters the theoretical apparatus of logic and mathematics, but this very person is unable to apply it in practical life.

Thus, Gadamer concludes that transcendental forms of experience occupy the highest level of knowledge, surpassing the research sciences' truth. Moreover, the understanding obtained in the so-called "non-scientific experience" is much more effective than a simple experimental coincidence (correspondence) of knowledge and reality. That is, here, transforming the famous statement by R. Rorty, one can say that the methodological means of philosophical hermeneutics transform philosophy from a "mirror of nature" to a kind of "experience of nature". However, such an experience makes individual demands on cognition.

Taking this into account, it can be stated that Gadamer's understanding of the truth differs significantly from its traditional understanding.
The truth in this context is actualised not simply as a consequence of traditional experience and its mental processing, but rather as a historical process of revealing the essence of a thing, which is by no means connected with the logic of judging the correspondence between the mind and the thing. It turns into a process that defines a person, his personal relation to the thing. Moreover, the preliminary knowledge of the thing, obtained as a result of traditional scientific experience, acts as a kind of material, a springboard for the action of the human being's transcendental essences.

Therefore, Gadamer believes that the researcher-interpreter, revealing the essence of the thing with the help of his own transcendental features, expresses a personal attitude to the thing and frees himself from reality, into which he has been included in advance. This is precisely the peculiarity of understanding in the context of humanities: it is aimed at identifying the onetime and uniqueness of the process which is explored. Understanding is carried out by abstraction from the visibility of everyday experience and the introduction of speculative constructions. Empirical verification is assumed. Ethical and aesthetic statements, with the help of which a person evaluates works of art and any actions, should be considered sentences devoid of meaning.

The thinker believes that there is a world experience that cannot be revealed exclusively with the abstract methodology of natural science. So, in the bosom of humanities, it is necessary to speak about a special mechanism of understanding, which, in fact, is the essence of the hermeneutic method. It, according to Gadamer, consists of four initial components, which are considered comprehensively: education (Bildung, paideia), common sense (Sensus communis), judgment ability, and taste. 
The category of education is considered by Gadamer much broader than the simple development of human abilities and talents. Education is not only a process but also its result, which takes root in the formation of a kind of educational consciousness or a specific and universal feeling. However, this feeling, in contrast to the traditional senses of sight, hearing, taste, and smell, which are realised in their own planes, acts in all directions simultaneously; that is, it is a common feeling. "Education should be understood not only as a process that provides a historical upsurge of the spirit in the field of the universal; at the same time, it is the element in which the educated person is" (Gadamer, 1991, p. 56).

Thus, speaking about an educated person, Gadamer (1988) does not mean the level of assimilation of certain norms of humanitarian science, but the formation of a special humanitarian feeling that allows a person to understand: "the general essence of human education is that a person makes himself in all respects a spiritual being" (p. 53).

Describing the categories of "judgment ability" and "common sense" (Sensus communis), somehow connected with the essence of hermeneutic understanding, Gadamer (1988) alludes to the point of view according to which "... there has long been a kind of knowledge that the possibilities of rational proof and learning are not completely exhausting the sphere of knowledge" (p. 66). Hence, these categories must be distinguished since the first of them forms true knowledge, and the second - only probabilistic. It is necessary to dwell on this thesis in more detail.

If traditional logic since the time of Aristotle has understood the ability to judge as an abstract property of thinking inherent in any person, namely the summing up of the individual under the general, then under the concept of the category of "common sense" Gadamer understands a positive ethical motive for overcoming a specific situation when the goal is to do something right. In other words, common sense is not just the ability to judge, and it evaluates the correspondence of knowledge about reality directly to this reality. It requires the implementation of not only a true conclusion but also a correct conclusion, that is, one that is motivated by certain realities of reality, and therefore carries not only a rational but also a sensual load. It is not a simple statement of a certain fact (its experience confirmation) but a guide to action, which is based on a combination of truth and moral motives. "Moral motives in the concept of common sense or good sense (common sens, bon sens) are still valid today and distinguish this concept from our concept of common sense," Gadamer writes in this regard. "...Common mind, common sense, is primarily manifested in the judgments about the right and the wrong, the suitable and the unsuitable, which it makes. The possessor of a sound judgment is not only able to define the special from the point of view of the general, but he knows what it really refers to, that is, he sees things from the correct, fair, healthy point of view" (Betti, 2011, pp. 68-74). That is, "common sense" the thinker puts a step higher than "judgment". It is common sense that the human capacity for judgment passes from the theoretical to the practical dimension.

Finally, the last component of hermeneutic understanding, according to Gadamer, is taste. This category objectively complements the categories of common sense and judgment and belongs to human sensuality, giving it a moral and aesthetic burden. Nevertheless, if common sense and the ability to judge are based on the objec- 
tions of the "right-wrong", "true-false", then the foundations of taste must be sought in the polarity of the "appropriate-inappropriate". However, taste should also be considered as a particular way of cognition because "it belongs to the area where by the reflecting ability of judgment on the singular the common recognises to which it is subject. Taste, like the ability to judge, is the definition of the singular in the light of the whole: whether the singular is suitable for all others and, therefore, whether it is "appropriate" or not" (Gadamer, 1991, p. 80).

\section{Conclusion}

1. The process of hermeneutic understanding is one of the most challenging problems of modern philosophy. The difficulty here is that the original components of understanding, successfully characterised by Gadamer, are historically variable, such that they have lost their methodological purpose under the weight of the standards of scientific methods of the Modern era. Nevertheless, the understanding, according to Gadamer's deep conviction, ends in the application. Therefore, further searches for the latest hermeneutic methodologies are doomed to exist.

2. Transcendental forms of experience occupy the highest level of knowledge, surpassing the truth produced by the research sciences.

3. Gadamer's understanding of truth is significantly different from its traditional understanding. Truth in this context is actualised not merely as a consequence of traditional experience and its mental processing but rather as a historical process of revealing the essence of a thing, which is not related to the logic of judging the correspondence of reason and thing.

\section{References}

Betti, E. (2011). Germenevtika kak obshchaya metodika nauk o dukhe (Hermeneutics as a General Technique for the Sciences about the Spirit, in Russian). Moscow: Izd-vo "Kanon + ROOI Reabilitatciia".

Gadamer, H.-G. (1988). Istina i metod: Osnovy filosofskoi germenevtiki (Truth and Method: Fundamentals of Philosophical Hermeneutics, in Russian). Moscow: Progress.

Gadamer, H.-G. (1991). Aktual'nost' prekrasnogo (Relevance of the Beautiful, in Russian). Moscow: Iskusstvo.

Liakh, V. V., Yosypenko, O. M., Liubyvyi, Ya. V., Pazenok, V. S., Raida, K. Yu., \& Sytnychenko, L. A. (2017). Sotsiokulturni ta teoretychni zasady filosofii postmodernu (Sociocultural and Theoretical Foundations of Postmodern Philosophy, in Ukrainian). Kyiv: Vyd-vo Natsionalnoi Akademii Nauk Ukrainy. Instytut filosofii imeni H. S. Skovorody. 